\title{
FORMAÇÃO CONTINUADA DOS PROFESSORES DAS ESCOLAS TÉCNICAS DA UNIVERSIDADE FEDERAL DE SANTA MARIA
}

http://dx.doi.org/10.5902/2318133817382

\author{
Paola Mendes Milanesi \\ Caciara Gonzatto Maciel \\ Graziela Piveta \\ Rogério Gonzatto \\ Karla Marques da Rocha \\ Universidade Federal de Santa Maria, Brasil.
}

\begin{abstract}
Resumo
Neste texto destaca-se a importância da formação continuada de professores, tendo como objetivo analisar a participação dos docentes dos Colégios Politécnico e Técnico Industrial - Ctism - da Universidade Federal de Santa Maria - UFSM - em cursos de formação continuada. Para isso, foi realizada uma pesquisa quantitativa, sendo os dados coletados por meio de um questionário de múltipla escolha que foi aplicado para os docentes das referidas instituições. Concluiu-se que a maioria dos professores dos colégios Politécnico e Ctism da UFSM participam de cursos de formação continuada e recebem incentivos das suas instituições. Ainda, os professores frequentam cursos de atualização na área da educação, mesmo aqueles que estão inseridos em áreas mais técnicas.
\end{abstract}

Palavras-chave: atualização profissional, ensino tecnológico.

\section{CONTINUING EDUCATION OF TEACHERS FROM TECHNICAL SCHOOLS OF THE FEDERAL UNIVERSITY OF SANTA MARIA}

\begin{abstract}
This article highlights the importance of the presence of teachers in continuing education courses, aiming to analyze the participation of teachers of Polytechnic and Technical Industrial - Ctism Colleges of Federal University of Santa Maria - UFSM - in continuing education courses. For this, we conducted a quantitative survey and the data collected through a multiple choice questionnaire that was applied to teachers in these institutions. It was concluded that most teachers of Polytechnic and Ctism Colleges of UFSM participate in continuing education courses and institutions to receive this incentive. Still, teachers attend refresher courses in education, even those that are embedded in more technical areas.

Key-words: professional development, technological education.
\end{abstract}




\section{Introdução}

formação continuada para professores é um processo necessário para a
melhoria da qualidade da educação técnica e profissional. Esse processo não
deve acontecer apenas no âmbito de aperfeiçoamento na área específica de sua formação, mas também no que diz respeito à sua formação pedagógica a fim de utilizar adequadamente metodologias alternativas de ensinagem. Para Tardif (2000) os conhecimentos profissionais são evolutivos e progressivos, tanto em suas bases teóricas quanto em suas consequências práticas e, dessa maneira, necessitam de uma formação contínua.

Há uma notória preocupação com o permanente processo de formação continuada dos professores, independente da modalidade de ensino em que estão inseridos. Por isso, esse tema vem assumindo posição de destaque nas discussões sobre a qualidade de ensino, bem como na proposição das políticas públicas e sobre como a formação continuada pode se articular com os conceitos de escola, ensino e currículo (Pérez Gómez, 1995). Para esse autor, o professor deve ser visto de duas formas distintas que expressam as suas concepções educativas na atividade do docente como profissional: como um profissional técnico-especialista e como um profissional reflexivo.

No centro dessas discussões, a formação continuada aparece associada ao processo de melhoria das práticas pedagógicas desenvolvidas pelos professores em sua rotina de trabalho e em seu cotidiano escolar. Alguns autores já apontam a necessidade de pesquisa e discussão sobre essa formação (Nóvoa, 1991; Veiga, 1998; Perrenoud, 2000; Carvalho, 2005), pois na perspectiva dos estudos sobre o tema, a formação continuada é tida como necessária não somente para tentar minimizar as lacunas da formação inicial, mas por ser a escola um espaço privilegiado de formação e de socialização entre os professores, nas quais se atualizam e se desenvolvem saberes e conhecimentos docentes. Além disso, também é possível trocar experiências entre pares (Bernado, 2003).

De forma geral, a docência na educação profissional é exercida por pessoas com formação na área técnica, sem formação pedagógica antes ou durante o exercício da mesma. Esses profissionais muitas vezes possuem experiências baseadas em uma visão particular de mundo e profissional da área, o que poderá interferir em sua atuação na formação de novos alunos. Nesse sentido, estudos que abordem a realidade complexa em que os professores dessa modalidade de ensino estão inseridos, devem ser motivados a fim de compreender qual é o sentido de uma formação continuada para esses indivíduos (Burnier e Gariglio, 2010).

Um dos questionamentos levantados durante os estágios supervisionados referentes ao Programa Especial de Graduação para a Educação Profissional e Tecnológica da UFSM foi o índice de participação dos professores em cursos que proporcionem a atualização de conteúdos e para a melhoria de sua formação pedagógica a partir de metodologias aplicadas em sala de aula. Além disso, o processo de formação continuada deve ser valorizado porque é a partir dele que o ensino poderá sanar defasagens muitas vezes encontradas na prática docente (Fávero et al., 2013). 
Canen e Xavier (2011) consideram a formação de professores, seja ela inicial ou continuada, um lugar privilegiado, não só para refletir e discutir sobre as questões que envolvem a diversidade cultural brasileira, como para a criação e a implementação de ideias que possibilitem nortear novos caminhos e avanços no que tange a esse assunto. Segundo Gariglio e Burnier (2012) o conhecimento técnico é fundamental, mas não único, e os cursos de formação, quando realizados com integralidade própria, auxiliam no processo de profissionalização.

Nesse sentido, o objetivo deste trabalho foi analisar como e com qual frequência os professores dos Colégios Politécnico e Técnico Industrial - Ctism - da UFSM participam de cursos de formação continuada. Para isso, foi realizada uma pesquisa qualitativa e quantitativa, sendo os dados coletados através de um questionário aplicado ao corpo docente das referidas instituições. Os profissionais tiveram um prazo de 15 dias para emitir as respostas. Na sequência os dados foram processados e organizados em gráficos, para melhor apresentar a realidade dos questionamentos em cada instituição.

O Colégio Politécnico é uma unidade de ensino médio, técnico e tecnológico da Universidade Federal de Santa Maria, cuja finalidade é ministrar a educação básica, a formação inicial e continuada, a educação profissional técnica de nível médio e a educação profissional tecnológica. São oferecidos os seguintes cursos técnicos: Administração; Agroindústria; Agropecuária; Contabilidade; Geoprocessamento; Informática; Meio Ambiente e Paisagismo. Já o Colégio Técnico Industrial de Santa Maria - Ctism - é uma escola técnica federal, vinculada à Universidade Federal de Santa Maria, subordinada à Coordenadoria de Ensino Médio e Tecnológico da UFSM. São oferecidos os seguintes cursos técnicos: Eletrotécnica; Mecânica; Eletromecânica; Automação Industrial; Eletrônica; e Segurança do Trabalho. Além disso, o Ctism também oferece à modalidade de Ensino à Distância.

\section{Formação continuada no Colégio Politécnico da UFSM}

Obteve-se 31 questionários respondidos no Colégio Politécnico. Destes, 12 pessoas são do sexo feminino e 17 do sexo masculino. A faixa etária predominante foi de 30-40 anos. A participação dos professores em cursos de formação continuada está dividida em três grandes áreas que predominam na instituição: Ciências Naturais e da Terra, Ciências da Informação e Ciências Sociais e Humanas, gráfico 1. 
Gráfico 1 -

Participação dos professores do Colégio Politécnico da UFSM em cursos de capacitação.

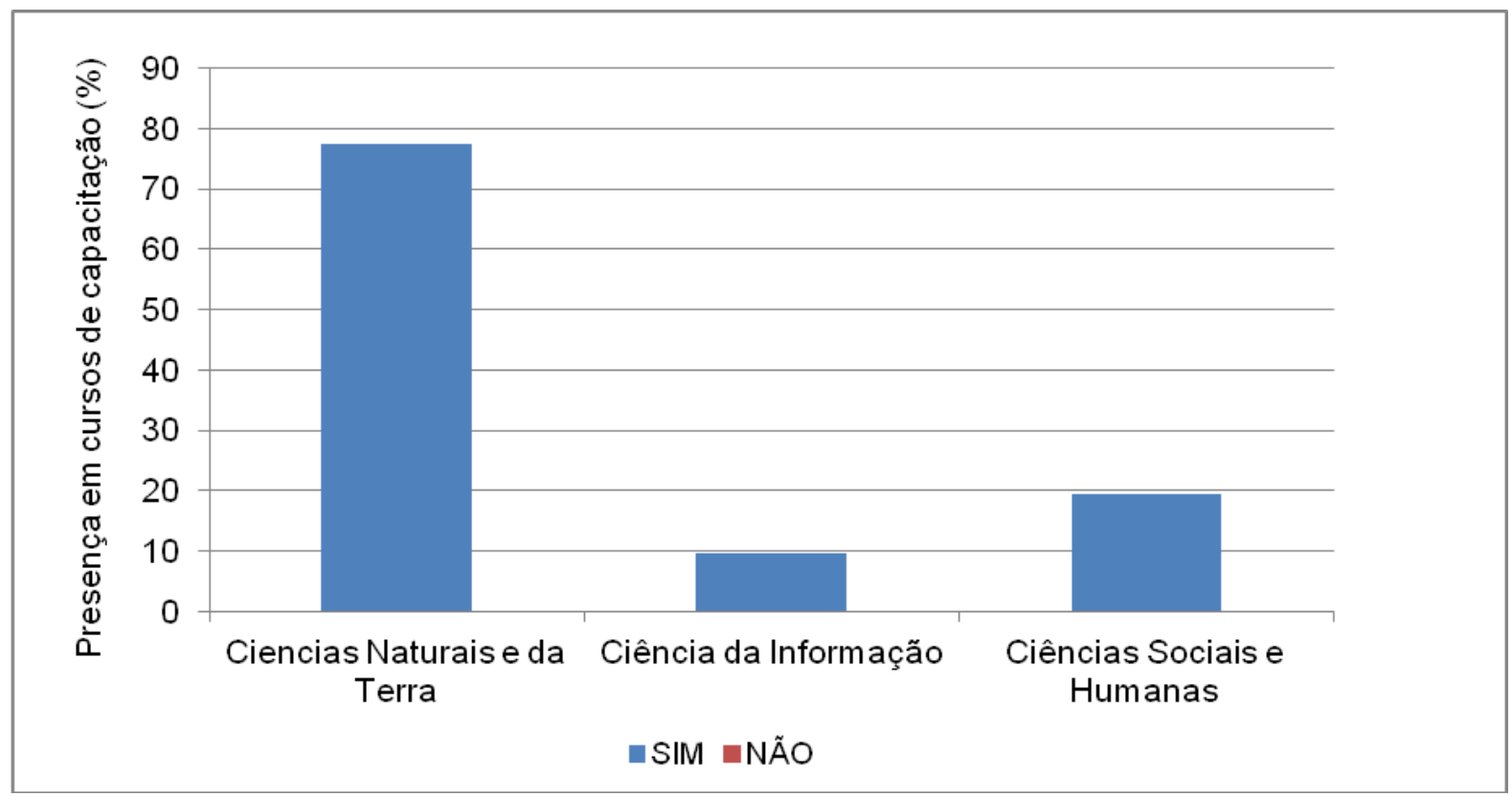

Notou-se que todos os professores que responderam ao questionário costumam frequentar cursos de formação e, quando questionados sobre os pontos positivos dessa participação, eles salientaram a atualização de conhecimentos e trocas de experiências. Nessas dimensões, a formação continuada apareceu associada ao processo de melhoria das práticas pedagógicas desenvolvidas pelos professores em sua rotina de trabalho e em seu cotidiano escolar (Bernardo, 2004).

Em relação a frequência de participação nos cursos de formação, os professores das áreas da Ciência da Informação e Ciências Sociais e Humanas, tem presença mensal, enquanto que nas Ciências Exatas e da Terra a presença predominate é anual gráfico 2. Conforme verifica-se no gráfico 3, no que tange as áreas em que os professores estão realizando os cursos de capacitação, pelo menos, uma parcela deles está envolvido em cursos de formação na área da educação. Isso aponta que os professores assumiram o comprimisso de investigadores em sala de aula e que percebem a necessidade da atualização profissional, pois a formação se dá em momentos de integração da teoria com a prática investigativa. 
Gráfico 2 -

Frequência de participação de professores do Colégio Politécnico da UFSM em cursos de capacitação.

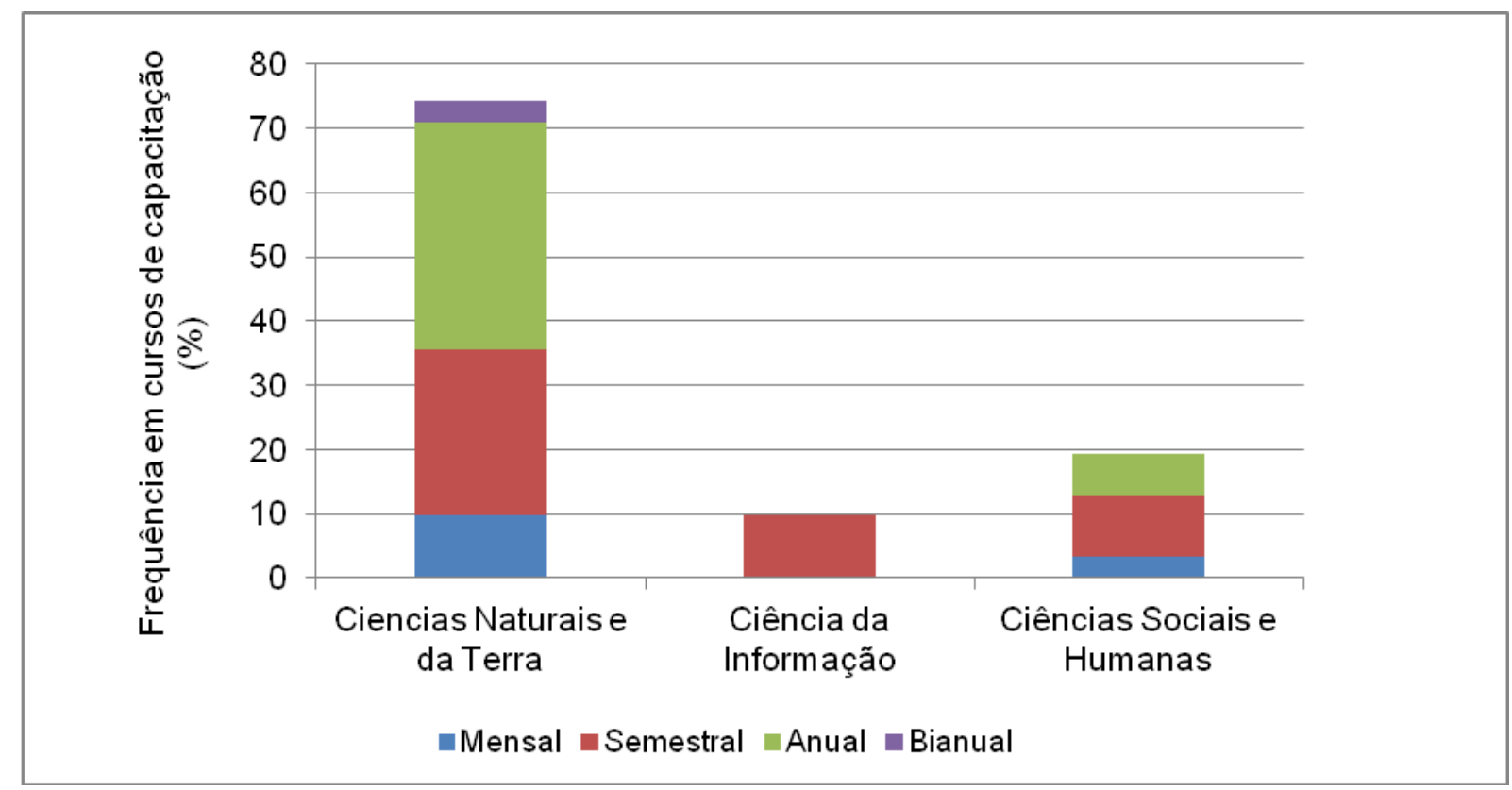

Gráfico 3 -

Áreas de capacitação dos professores do Colégio Politécnico da UFSM.

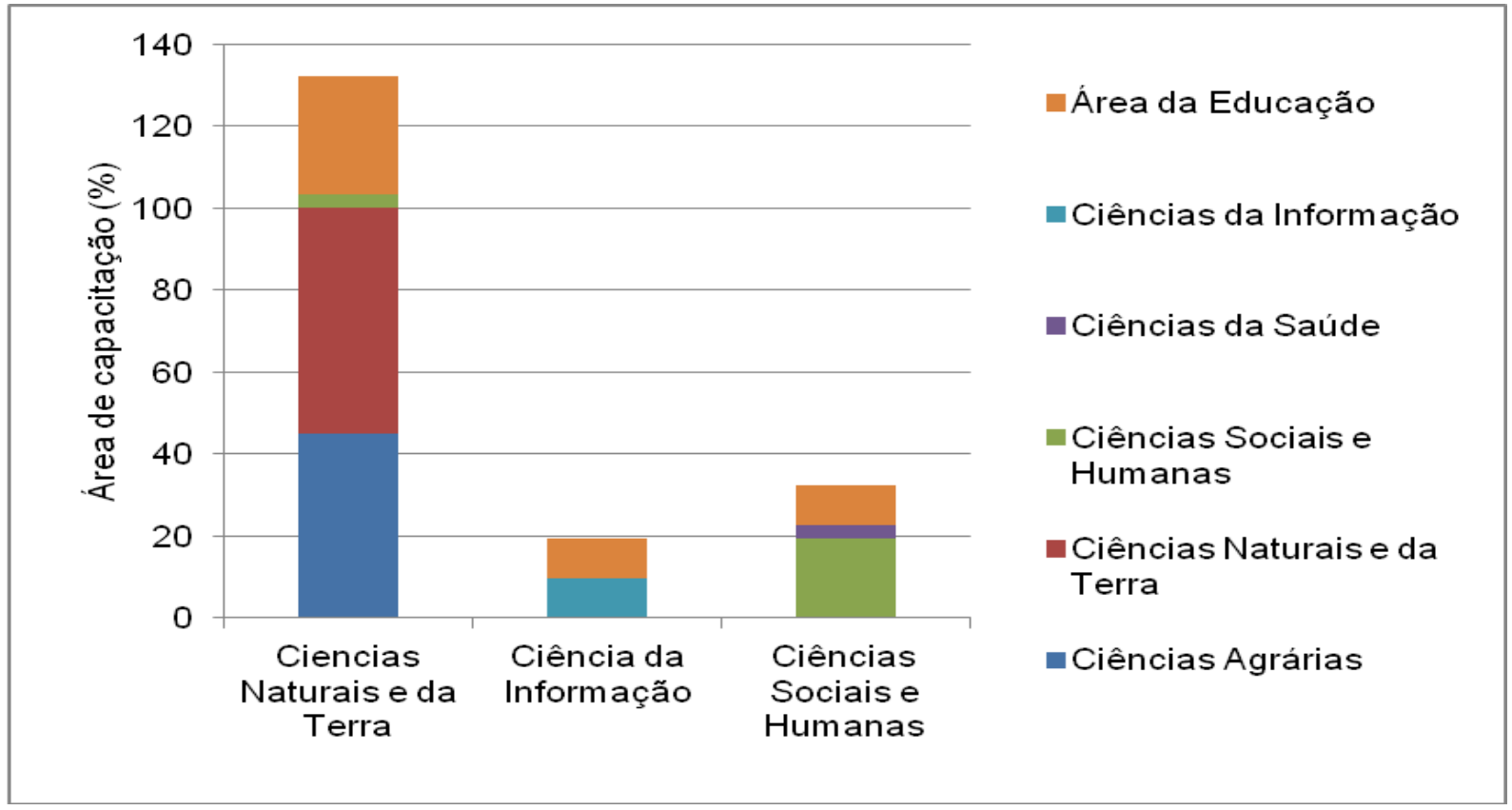

De acordo com Gatti (2008), na última década, a preocupação com a formação de professores entrou na pauta mundial, seja pelas pressões do mundo do trabalho, que estão estruturadas em novas condições, num modelo informatizado e com o valor 
adquirido pelo conhecimento, ou pelos sistemas de governo visto os precários desempenhos escolares da grande parcela da população. $\mathrm{Na}$ presente pesquisa os professores relataram, em sua grande maioria, receber incentivo financeiro da instituição para a participação de cursos de formação e mais de $60 \%$ dos entrevistados afirmaram que esse incentivo é integral.

\section{Formação continuada no Colégio Técnico Industrial - Ctism - da UFSM}

Obteve-se 15 questionários respondidos no Colégio Técnico Industrial. Destes 8 pessoas são do sexo feminino e 7 são do sexo masculino. A faixa etária predominante foi entre 50-60 anos. A participação dos professores em cursos de formação continuada está dividida em duas grandes áreas: Ciências Naturais e da Terra e Ciências Sociais e Humanas (gráfico 4).

Gráfico 4 -

Participação dos professores do Colégio Técnico Industrial da UFSM em cursos de capacitação.

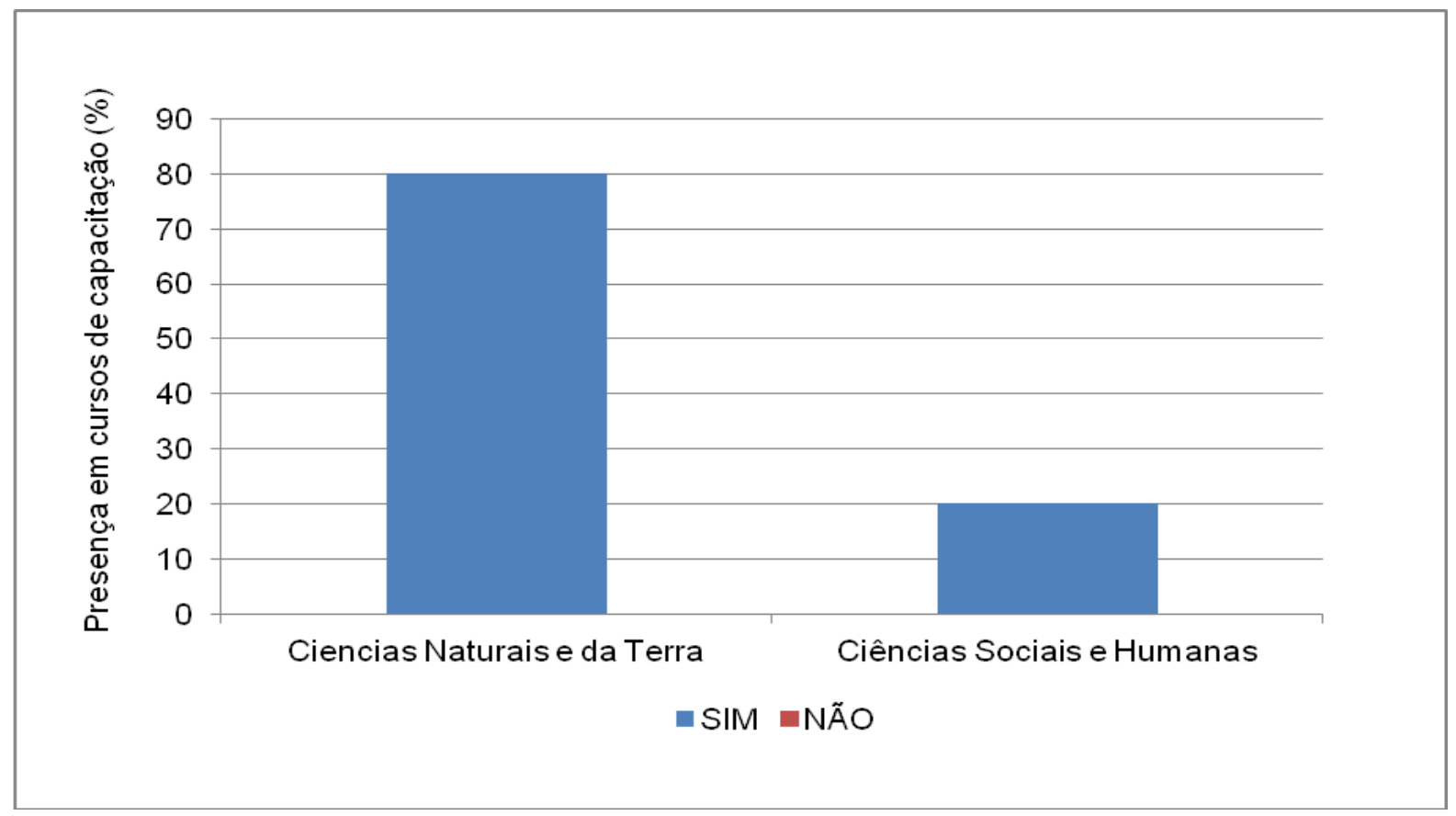

Constatou-se que todos os professores englobados pelo questionário tem participação em cursos de formação continuada. Quando questionados sobre a frequência de participação nos cursos de formação, os professores da área de Ciências Naturais e da Terra apresentam frequência semestral e anual, e os professores da área de Ciências Sociais e Humanas apresentaram frequência mensal, semestral e anual gráfico 5 . 
Gráfico 5 -

Frequência de participação de professores do Colégio Técnico Industrial da UFSM em cursos de capacitação.

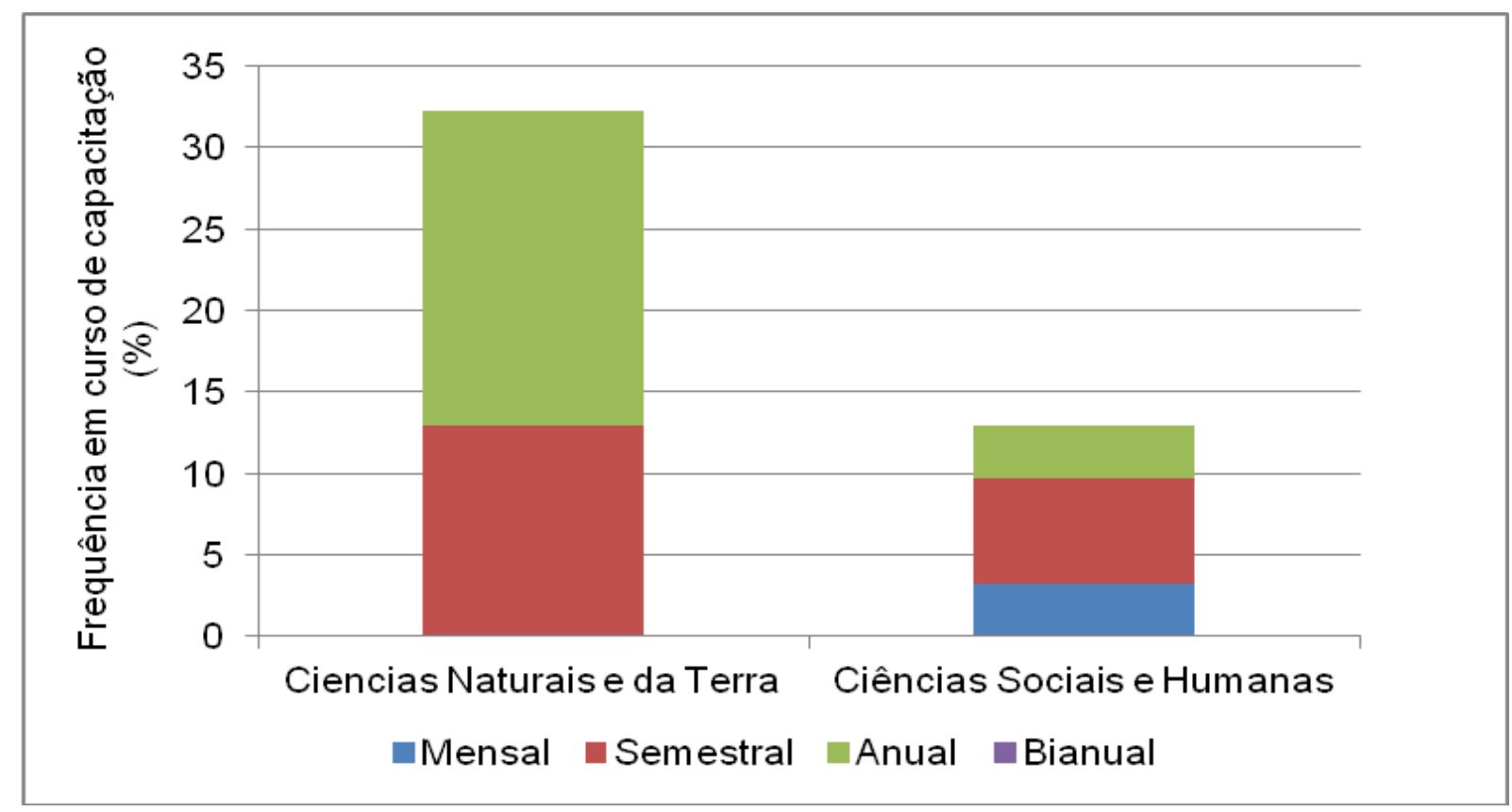

Ainda, foi possível observar que os professores frequentam predominantemente os cursos oferecidos na sua área de atuação, entretanto, a participação em cursos de atualização na área da educação é representativa (gráfico 6). Segundo Marcelo García (1999), o desenvolvimento profissional de professores se adapta ao conceito de professor como profissional do ensino e define-se como uma atitude permanente de pesquisa, de questionamento e busca de soluções. Portanto, a formação profissional docente é um processo individual e coletivo que se consolida nas diversas experiências e aprendizagens que envolvem o ato de ensinar. Conforme Day (2001, p. 91), "esse processo envolve todas as experiências espontâneas de aprendizagem e as atividades conscientemente planificadas, realizadas para benefício direto ou indireto do indivíduo, do grupo ou da escola e que contribuem, através destes, para a qualidade da educação na sala de aula."

Além disso, segundo esse autor, o desenvolvimento profissional permite superar os objetivos de simples aquisição de destrezas ou habilidades de ensino ou conhecimentos relativos ao conteúdo a ensinar e depende não somente dos aspectos profissionais, mas também pessoais dos professores, bem como das políticas e dos contextos escolares nos quais eles realizam a atividade docente.

Observou-se que os professores do Colégio Técnico Industrial da UFSM, em sua maioria, recebem incentivo financeiro integral da instituição para a participação de cursos de formação, mas não recebem nenhum tipo de bonificação salarial por isso. A formação continuada de professores pode ser considerada um recurso que mobiliza o professor a refletir criticamente sobre a sua prática no sentido de avaliá-la, compreendê-la e modificála. Em relação aos pontos positivos observados pelos professores do Ctism, destacaramse alguns aspectos como a atualização profissional, estabelecimento de novas parcerias

\begin{tabular}{|l|l|l|l|l|l|} 
Regae: Rev. Gest. Aval. Educ. & Santa Maria & v. 5 & n. 9 & Jan./jun. 2016 & p. 31-40
\end{tabular} 
e trocas de experiências. Segundo os entrevistados esses cursos são importantes para diversificação e complementação do conteúdo apresentado em sala de aula. Pontos negativos não foram apontados, exceto, o caso de alguns cursos de formação não contemplarem os assuntos previstos e, dessa maneira, não atenderem aos objetivos esperados.

Gráfico 6 -

Áreas de capacitação dos professores do Colégio Técnico Industrial da UFSM.

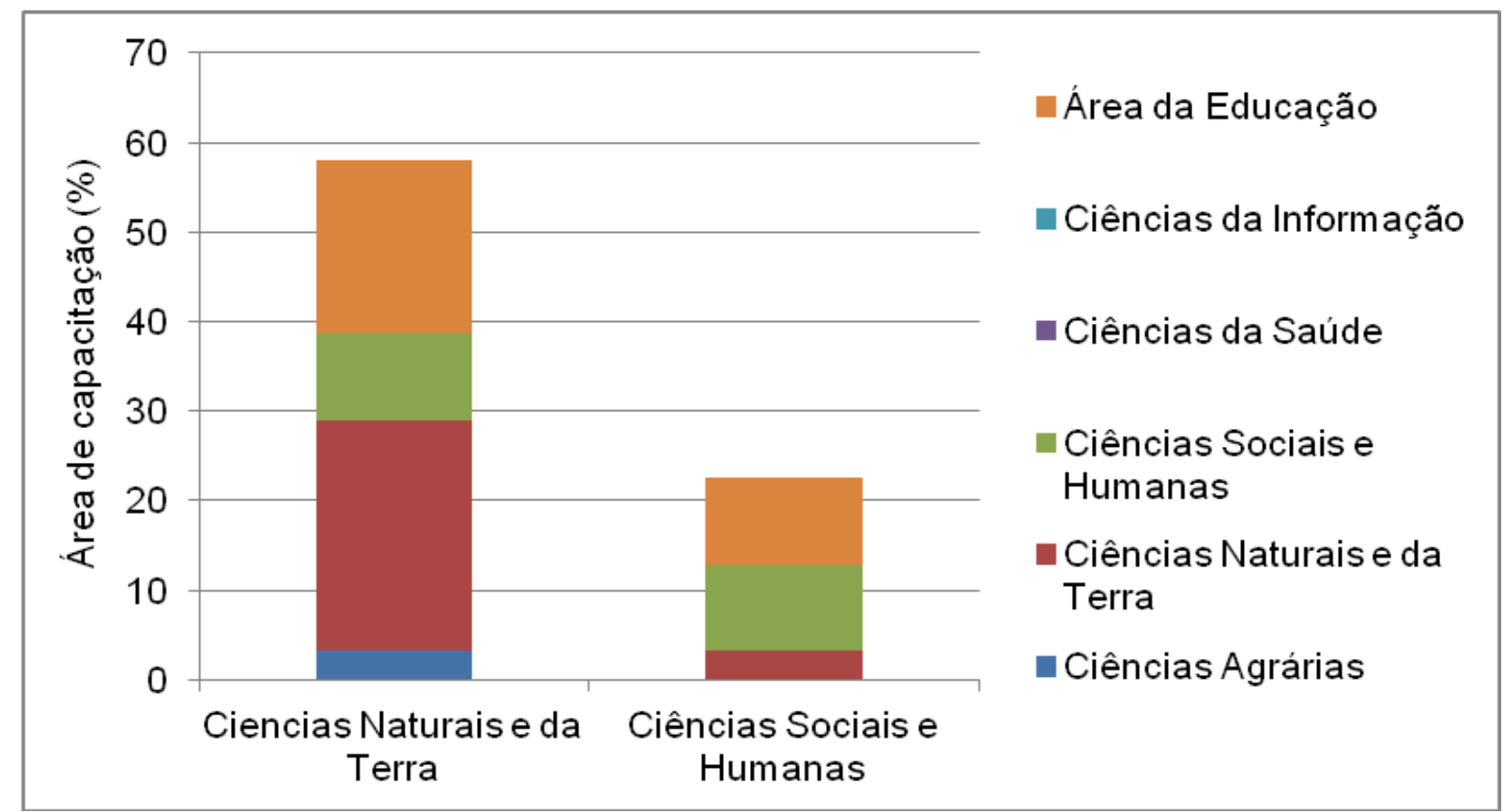

Quando comparada a participação em cursos de formação continuada dos docentes das duas instituições investigadas, verificou-se que eles têm como hábito frequentar cursos de capacitação em suas áreas de formação e na área da educação e são incentivados pelas instituições para isso. Não foi possível observar diferença entre as duas instituições, entretanto o número de questionários respondidos foi superior no Colégio Politécnico.

\section{Conclusão}

Inicialmente levantou-se a hipótese de que a maneira como as aulas eram conduzidas nas escolas técnicas estivesse relacionada com a falta de participação dos docentes em cursos de formação continuada. Porém, como foi constatado no presente trabalho, todos os professores entrevistados, dos Colégios Politécnico e Técnico Industrial da UFSM, participam de cursos de formação continuada e recebem incentivos das referidas instituições para isso. Sugere-se assim, que futuros estudos possam ser realizados em relação à qualidade desses cursos e se eles realmente atendem as necessidades pedagógicas e de atualização dos docentes, bem como a opinião dos alunos em relação à maneira como os conteúdos são apresentados em sala de aula. 


\section{Referências}

BERNADO, Elisangela da Silva. Formação continuada de professores em escolas organizadas em ciclo. PUC-RJ, 2003. 106f. Dissertação (mestrado em Educação). Programa de Pós-Graduação em Educação, Pontifícia Universidade Católica do Rio de Janeiro.

BERNADO, Elisangela da Silva. Um olhar sobre a formação continuada de professores em escolas organizadas no regime de ensino em ciclo(s). REUNIÃO ANUAL DA ANPED, 27, 2004, Caxambu. Anais ... Caxambu: Anped, 2004.

BRASIL. LDB - Lei n. 9394/96, de 20 de dezembro de 1996. Estabelece as diretrizes e bases da Educação Nacional. Brasília: MEC, 1996.

BURNIER, Suzana; GARIGLIO, José. Ângelo. O professor da educação profissional seus saberes, suas práticas e relação com a docência. ENCONTRO NACIONAL DE DIDÁTICA E PRÁTICA DE ENSINO, 15, 2010, Belo Horizonte. Anais ... Belo Horizonte, 2010, p. 1-40.

CANEN, Ana; XAVIER, Giseli Pereli de Moura. Formação continuada de professores para a diversidade cultural: ênfases, silêncios e perspectivas. Revista Brasileira de Educação, Rio de Janeiro, v. 16, n. 48, 2011, p. 641-663.

CARVALHO, Janete Magalhães. O não-lugar dos professores nos entre lugares de formação continuada. Revista Brasileira de Educação, Rio de Janeiro, n. 28, 2005, p. 96107.

DAY, Chistopher. Desenvolvimento profissional de professores: os desafios da aprendizagem permanente. Coleção Currículo, políticas e práticas. Porto: Porto, 2001.

FÁVERO, Altair Alberto; TONIETO, Carina; ROMAN, Marisa Fátima. A formação de professores reflexivos: a docência como objeto de investigação. Educação, v. 38, n. 2, 2013, p. 277-288.

GARIGLIO, José Ângelo; BURNIER, Suzana. Saberes da docência na educação profissional e tecnológica: um estudo sobre o olhar dos professores. Educação em Revista, Belo Horizonte, v. 28, n. 1, 2012, p. 211-236.

GATTI, Bernardete Angelina. Análise das políticas públicas para formação continuada no Brasil, na última década. Revista Brasileira de Educação, v. 13, n. 37, 2008, p. 57-70.

GARCÍA, Carlos Marcelo. A formação de professores: novas perspectivas baseadas na investigação sobre o pensamento do professor. In: NÓVOA, Antônio (org.). Os professores e a sua formação. Lisboa: Dom Quixote, 1995, p. 51-76.

NÓVOA, Antônio. Concepções e práticas da formação contínua de professores: In: NÓVOA Antônio (org.). Formação contínua de professores: realidade e perspectivas. Portugal: Universidade de Aveiro, 1991, p. 30-42.

PÉREZ GÓMEZ, Angel. O pensamento prático do professor: a formação do professor como profissional reflexivo. In: NÓVOA, Antônio (org.). Os professores e sua formação. Lisboa: Dom Quixote, 1995, p. 93-114.

PERRENOUD, Philippe. Pedagogia diferenciada: das intenções à ação. Porto Alegre: Artmed, 2000. 
TARDIF, Maurice. Saberes profissionais dos professores e conhecimentos universitários Elementos para uma epistemologia da prática profissional dos professores e suas consequências em relação à formação para o magistério. Revista Brasileira de Educação, Rio de Janeiro, n. 13, 2000, p. 5-24.

VEIGA, IIma Passos Alencastro. Caminhos da profissionalização do magistério. Campinas: Papelivros, 1998.

Paola Mendes Milanesi é graduada em Agronomia pela Universidade Federal de Santa Maria, com mestrado e doutorado em Agronomia pela mesma instituição. É professora no curso de Agronomia da Universidade Federal da Fronteira Sul, campus de Erechim.

Endereço: Universidade Federal da Fronteira Sul, campus de Erechim Rodovia ERS 135 - Km 72, 200 - 99700-970 - Erechim - RS - Brasil.

E-mail: paola.milanesi@uffs.edu.br.

Caciara Gonzatto Maciel é engenheira florestal formada pela UFSM, com mestrado na mesma área. É doutoranda pelo Programa de Pós-graduação em Engenharia Florestal da UFSM. É professora na Universidade do Oeste de Santa Catarina.

Endereço: Avenida Roraima, 1000, prédio 42 - 97105-900 - Santa Maria - RS Brasil.

E-mail: caciaragonzatto@gmail.com.

Graziela Piveta é engenheira florestal formada pela UFSM, com mestrado e doutorado na mesma área. É pós-doutoranda na área de Fitopatologia Florestal na Universidade do Centro Oeste do Paraná.

Endereço: Universidade Estadual do Centro-Oeste do Paraná, campus de Irati, Rodovia PR 153, Km 7 - 84500-000 - Irati - PR - Brasil.

E-mail: grazipiveta@yahoo.com.br.

Rogério Gonzatto é engenheiro agrônomo, mestre em Ciência do Solo. É aluno de doutorado do Programa de Pós-Graduação em Ciência do Solo na UFSM.

Endereço: Av. Roraima, 1000 - 97105-900 - Santa Maria - RS - Brasil.

E-mail: rogonzatto@gmail.com.

Karla Marques da Rocha é professora na Universidade Federal de Santa Maria.

Endereço: Av. Roraima, 1000 - 97105-900 - Santa Maria - RS - Brasil.

E-mail: karlarocha@terra.com.br.

Recebido em 19 de março de 2015.

Aceito em 29 de agosto de 2015. 